\title{
Effect of Dietary Modification for Targeting \\ Histamine Activity in Patients of Allergic Rhinitis: a Randomised Open Label Study
}

Mohsin Ali Khan

Era University

Zaw Ali Khan ( $\square$ zawali@erauniversity.in )

Era University https://orcid.org/0000-0002-8418-8068

Abdul Naeem

Era University

Nigar Naqvi

Era University

Shikha Srivastava

Era University

Anuja Bhargava

Era's Lucknow Medical College \& Hospital

Rajeev Krishna Gupta

Era's Lucknow Medical College \& Hospital

\section{Research Article}

Keywords: allergy, rhinitis, histamine, inflammation, diamine oxidase, diet

Posted Date: April 29th, 2020

DOl: https://doi.org/10.21203/rs.3.rs-25717/v1

License: (c) (i) This work is licensed under a Creative Commons Attribution 4.0 International License. Read Full License 


\section{Abstract}

Allergic Rhinitis refers to immunoglobulin E mediated inflammation of the nasal cavity. Mast cell activation releases histamine, the inflammatory mediator that plays a central role in the biochemical mechanism of this disease. It is metabolised by Diamine Oxidase (DAO) and Histamine Nmethyltransferase (HNMT). In this randomised open label study, we recruited 60 patients out of which 30 patients were provided standard treatment and 30 were provided standard treatment along with instructions for dietary modification. The dietary modification consisted of excluding commonly consumed histamine-rich foods and foods containing pro-histamine or anti-DAO active constituents. Each patient was followed up 3 times over the course of 15 days. The patients in the dietary modification group showed significant improvement in rhinitis symptoms within 7 days, while the control group's improvement was not significant in the same amount of time. The overall improvement between the first and last visits was more significant in the dietary modification group as compared to the control group. Thus, the exclusion of histamine-rich foods and foods containing pro-histamine or anti-DAO compounds may be recommended to patients of allergic rhinitis for quicker and better recovery. This approach may also be explored in other conditions where histamine is implicated such as asthma and infections caused by coronaviruses.

\section{Introduction}

Rhinitis is the inflammation of the mucous membrane inside the nose which is defined by a combination of two or more nasal symptoms-running, blocking, itching and sneezing1. Allergic rhinitis (AR) is a nasal airway disease that occurs when these symptoms are the result of Immunoglobulin E (IgE) mediated inflammation following exposure to an allergen 2 . AR is a global health problem that is increasing in prevalence 3,4 . Globally, allergic rhinitis affects between $10 \%$ and $30 \%$ of the population 5 . Reported incidence of allergic rhinitis in India also ranges between $20 \%$ and $30 \% 6$.

Histamine is a biogenic amine that plays an important role in the lgE- mediated inflammatory response within the body. Endogenous histamine is synthesized from L-histidine by enzyme-dependent histidine decarboxylation [Fig. 1]. Most of the synthesis of histamine takes place in mast cells and basophils, which store it in large quantities and release it when they are degranulated in response upon immunological or non-immunological stimulus. Other cells such as dendritic cells and lymphocytes secrete histamine immediately after producing it upon stimulation7,8. Certain foods that are rich in histamine can also increase the bioavailability of histamine [Fig 1]. The released histamine produces diverse biological effects including inflammation, vasodilation, decreased peripheral resistance, airway smooth muscle contraction, and sensory nerve stimulation 9,10.

In a healthy individual, histamine is broken down on a regular basis by two enzymes: Diamine Oxidase (DAO) and Histamine N-methyltransferase (HNMT) [Fig. 2]. DAO is found in the intestinal mucosa and is the primary enzyme for the metabolism of histamine in gut and extracellular space, while HNMT is the primary enzyme for the degradation of histamine in intracellular tissues. Histamine intolerance can occur 
when DAO or HNMT enzyme activity is insufficient. It is described as an excess of histamine in the blood circulation, gives rise to an array of symptoms that are typical in allergic reactions 11 .

Histamine, its activators and DAO inhibitor are present in some everyday dietary products such as egg white, tomatoes, peanuts, almonds, alcohol etc. [See Table 1]. These food products may increase histamine bioavailability, increase its activity or decrease the activity of DAO. Thus, consumption of these food products can exacerbate the inflammatory symptoms of rhinitis. Through this study, we aim to assess the effect of restricting the dietary intake of these foods on the severity of symptoms in patients of allergic rhinitis.

Table 1 - Foods Products That Increase The Bioavailability and Activity of Histamine 


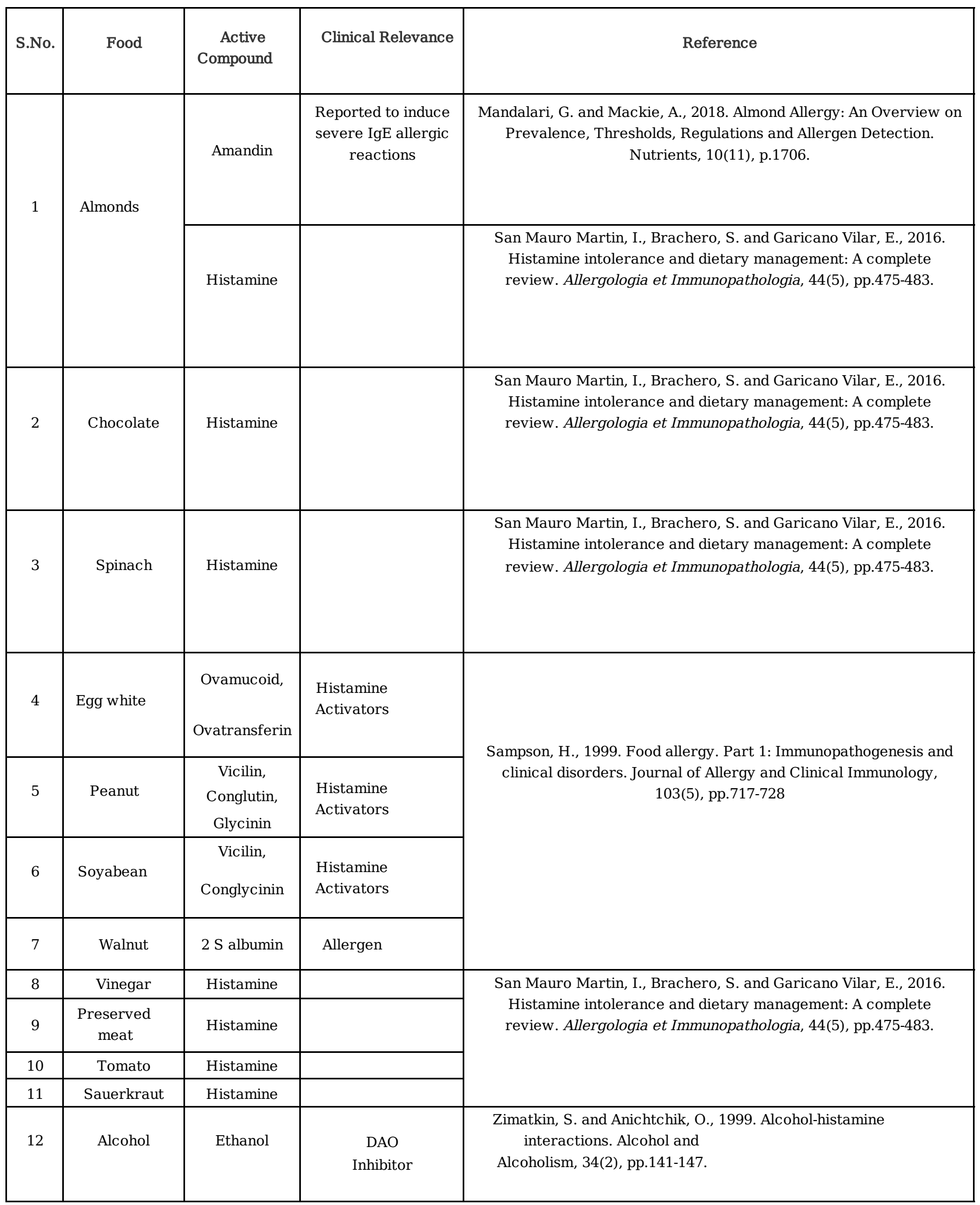

\section{Materials And Methods}

\section{A prospective study was done in the Department of Otorhinolaryngology, Head and Neck Surgery, Era's Lucknow Medical College, Era University. A total of 60 patients were enrolled for the study during a 3}


months period from Dec '18- Feb'19 based on inclusion and exclusion criteria. Diagnosis of Allergic Rhinitis was made based on the guidelines of ARIA12 (Allergic Rhinitis and its Impact on Asthma), a nongovernmental organization which collaborates with the World Health Organization (WHO) through the Global Alliance Against Chronic Respiratory Diseases (GARD).

The symptoms were assessed by Rhinitis Control Assessment Test (RCAT) Score13 [Annexure 1] and signs by Anterior Rhinoscopy score [Annexure 2]. RCAT is a brief, patient-completed tool to evaluate rhinitis symptom control. The RCAT has demonstrated adequate reliability, validity, and responsiveness and is deemed acceptable and appropriate by patients. RCAT has 6 items that include nasal congestion, sneezing, watery eyes, avoiding activities which predispose to allergy, how well allergic symptoms were controlled last week and sleep problems caused by rhinitis. For each of the items, responses are measured on 5-point Likert-type scales. RCAT scores range from 6 to 30, with higher scores indicating better rhinitis control. Anterior Rhinoscopy Score has 4 items which includes nasal discharge, nasal mucosa colour, inferior turbinate hypertrophy and nasal obstruction. The score ranges from 0 to 1 , lower score indicating better rhinitis control.

Patients were randomized by computer generated tables into 2 subgroups comprising 30 patients in each group. The allocation of patients into two groups was done by serially numbered opaque sealed envelope technique. Patients in Group 1 were given Standard treatment of allergic rhinitis and patients in Group 2 were given standard treatment along with dietary modification in which pictorial list of food items to be avoided in the diet was given [See Annexure 3]. The food items listed were all known to contain high levels of histamine or pro-histamine active constituents or inhibitors of diamine oxidase. All 60 patients were asked to record food items consumed at home daily. Patients were followed up at the end of 3,10 and 15 days and they were re-assessed on the grounds of RCAT score and Anterior Rhinoscopy score. If the subject did not come for follow up a telephonic counselling was done for reporting in the hospital. If the subject did not agree, RCAT was assessed on phone and included in the result separately.

\section{Inclusion criteria:}

1. All new patients with mild to moderate types of allergic rhinitis based on ARIA

2. Patients aged 12 years to 70 years and of both

3. Patients of both seasonal and perennial types of allergic

\section{Exclusion criteria}

1. Immuno-compromised patients including HIV positive patients and patients on prolonged steroid use

2. Patients of any chronic illnesses like CKD, TB,

3. Any patient who has received immunotherapy for allergic

4. Patients of severe Allergic 
In a parallel study we followed 252 patients of allergic rhinitis in the hospital from September 2018 to March 2020. Dietary intervention included omission of certain foods that were suspected to aggravate allergic rhinitis e.g., tomatoes, peanuts, processed meat. etc and inclusion of certain type of foods such as cinnamon etc (see Annexure 4). Patients were followed up weekly and their symptoms were recorded. Patients were also followed up on phones if they could not come to hospital.

\section{Results}

This study was conducted on a total of 60 patients of age group varying from 14 years to 60 years. Maximum number of patients fell into the age group of 20-30 years. Out of 60 patients, males were 36 (60\%) and females were 24 (40\%). The flowchart of the follow up is depicted in Figure 3 . The mean RCAT scores for each group are listed in Table 2(a), 2(b), 2(c) and 2(d) for intragroup comparison and in Table 3 for intergroup comparison. The changes in scores with each visit are depicted graphical in Figure 4.

While the mean RCAT values between visit 1 and visit 2 increased in both the groups, indication

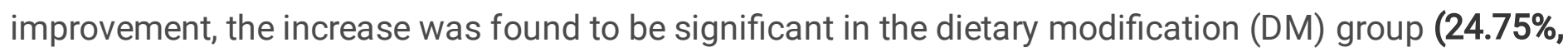
$\mathrm{p}=\mathbf{0 . 0 0 7 )}$ and not significant in the control group $(10.86 \%, \mathrm{p}=0.092)$.

Between the second and the third visit, there was a further increase $(15.89 \%)$ in the mean RCAT value of the DM group. However, the mean RCAT value of the control group decreased (-4.69\%) during the same time. While the intragroup changes in the mean RCAT value for neither of the two groups was not significant, the difference between the improvement of the DM group and the deterioration of the control group was significant $(\mathrm{p}=\mathbf{0 . 0 4 6})$.

There was an increase in the mean RCAT values for both the groups between visit 3 to visit 4 . The increase in the score of the DM group (10.29\%) was relatively more than the increase $(8.93 \%)$ in the score of the control group, but neither of the two increases was significant.

The overall increase in the mean RCAT value between visit 1 to 4 was significant in the DM group $(69.66 \%, p=0.009)$ and the control group $(28.79 \%, p=0.031)$, both. While this increase was relatively more in the dietary modification group, the difference between the improvements was not significant $(p=0.115)$.

Table 2(a) - Intragroup Comparison Between Visit 1 And Visit 2

\begin{tabular}{|c|c|c|c|c|c|c|}
\hline & \multicolumn{2}{|c|}{ Dietary Modification Group } & \multicolumn{2}{c|}{ Control Group } \\
\cline { 2 - 7 } & Number of Subjects & Mean & SD & Number of Subjects & Mean & SD \\
\hline RCAT- 1 & 14 & 14.43 & 3.63 & 19 & 16.47 & 3.95 \\
\hline RCAT- 2 & 14 & 18.00 & 3.44 & 19 & 18.26 & 5.00 \\
\hline Intragroup & t-value & 3.20 & t-value & 1.78 \\
Visit 1 - 2 & p-value & 0.007 & p-value & 0.092 \\
\cline { 2 - 7 } & & & & & & \\
\hline
\end{tabular}


Table 2(b) - Intragroup Comparison Between Visit 2 And Visit 3

\begin{tabular}{|c|c|c|c|c|c|c|}
\hline & \multicolumn{2}{|c|}{ Dietary Modification Group } & \multicolumn{2}{c|}{ Control Group } \\
\cline { 2 - 7 } & Number of Subjects & Mean & SD & Number of Subjects & Mean & SD \\
\hline RCAT- 2 & 9 & 16.78 & 2.44 & 14 & 18.29 & 4.63 \\
\hline RCAT- 3 & 9 & 19.44 & 3.88 & 14 & 17.43 & 3.76 \\
\hline Intragroup Visit 2 - 3 & t-value & 2.18 & t-value & 0.80 \\
\cline { 2 - 7 } & p-value & 0.061 & p-value & 0.439 \\
\hline
\end{tabular}

Table 2(c) - Intragroup Comparison Between Visit 3 And Visit 4

\begin{tabular}{|c|c|c|c|c|c|c|}
\hline & \multicolumn{3}{|c|}{ Dietary Modification Group } & \multicolumn{3}{|c|}{ Control Group } \\
\hline & Number of Subjects & Mean & SD & Number of Subjects & Mean & SD \\
\hline RCAT- 2 & 7 & 19.57 & 3.41 & 9 & 17.33 & 3.54 \\
\hline RCAT- 3 & 7 & 21.57 & 5.06 & 9 & 18.89 & 4.37 \\
\hline \multirow[t]{2}{*}{ Intragroup Visit 3 - 4} & t-value & \multicolumn{2}{|c|}{1.73} & t-value & \multicolumn{2}{|c|}{1.58} \\
\hline & $\mathrm{p}$-value & \multicolumn{2}{|c|}{0.134} & $\mathrm{p}$-value & \multicolumn{2}{|c|}{0.154} \\
\hline
\end{tabular}

Table 2(d) - Intragroup Comparison Between Visit 1 And Visit 4

\begin{tabular}{|c|c|c|c|c|c|c|}
\hline \multirow{2}{*}{} & \multicolumn{3}{|c|}{ Dietary Modification Group } & \multicolumn{3}{c|}{ Control Group } \\
\cline { 2 - 7 } & Number of Subjects & Mean & SD & Number of Subjects & Mean & SD \\
\hline RCAT- 2 & 7 & 12.71 & 2.06 & 9 & 14.67 & 4.36 \\
\hline RCAT-3 & 7 & 21.57 & 5.06 & 9 & 18.89 & 4.37 \\
\hline Intragroup Visit 1 - 4 & t-value & 3.78 & t-value & 2.62 \\
\cline { 2 - 7 } & p-value & 0.009 & p-value & 0.031 \\
\hline
\end{tabular}

The changes in SIGN score are listed in Table 4. The change in SIGN score between visit 1 and visit 2 was relatively more, indicating no improvement, in the control group $(0.21 \pm 0.71)$ than that in the DM group $(0.07 \pm 0.73)$. The difference was not found to be statistically significant $(p=0.733)$. 
The changes in SIGN score from visit 2 to visit 3 and from visit 3 to visit 4 were relatively more in the DM group $(0.11 \pm 0.78,0.29 \pm 0.76)$ than in the control group $(0.00 \pm 0.68,0.11 \pm 0.60)$. However, the differences between the changes of the two groups were not found to be statistically significant $(p=0.829, p=0.606)$.

The overall change in SIGN score from visit 1 to visit 4 was relatively more in the DM group $(0.43 \pm 1.27)$ than in the control group $(0.33 \pm 0.71)$, but the difference between these was not statistically significant $(p=1.000)$.

Table - 3 Intergroup comparison of RCAT

\begin{tabular}{|c|c|c|c|c|c|c|}
\hline \multirow{2}{*}{ Duration } & \multirow{2}{*}{$\begin{array}{c}\text { Dietary } \\
\text { Modification }\end{array}$} & \multicolumn{3}{|c|}{ RCAT change } & \multirow{2}{*}{ t-value } & \multirow{2}{*}{$\begin{array}{c}\mathrm{p}- \\
\text { value }\end{array}$} \\
\hline & & Mean & SD & $\begin{array}{c}\% \\
\text { change }\end{array}$ & & \\
\hline \multirow{2}{*}{$\begin{array}{l}\text { Visit } 1 \text { to } \\
\text { Visit } 2\end{array}$} & Yes & 3.57 & 4.18 & 24.75 & \multirow{2}{*}{1.177} & \multirow{2}{*}{.248} \\
\hline & No & 1.79 & 4.38 & 10.86 & & \\
\hline \multirow{2}{*}{$\begin{array}{l}\text { Visit } 2 \text { to } \\
\text { Visit } 3\end{array}$} & Yes & 2.67 & 3.67 & 15.89 & \multirow{2}{*}{2.120} & \multirow{2}{*}{.046} \\
\hline & No & -0.86 & 4.02 & -4.69 & & \\
\hline \multirow{2}{*}{$\begin{array}{l}\text { Visit } 3 \text { to } \\
\text { Visit } 4\end{array}$} & Yes & 2.00 & 3.06 & 10.29 & \multirow{2}{*}{.294} & \multirow{2}{*}{.773} \\
\hline & No & 1.56 & 2.96 & 8.93 & & \\
\hline \multirow{2}{*}{$\begin{array}{l}\text { Visit } 1 \text { to } \\
\text { Visit } 4\end{array}$} & Yes & 8.86 & 6.20 & 69.66 & \multirow{2}{*}{1.682} & \multirow{2}{*}{.115} \\
\hline & No & 4.22 & 4.84 & 28.79 & & \\
\hline
\end{tabular}

Table 4 - Intergroup Comparison of Sign Scores

\begin{tabular}{|c|c|c|c|c|c|c|}
\hline \multirow{2}{*}{ Time Intervals } & \multicolumn{2}{|c|}{ DIETARY } & \multicolumn{2}{c|}{ CONTROL GROUP } & \multirow{2}{*}{ z-value } & p-value \\
\cline { 2 - 6 } & $\begin{array}{c}\Delta \text { Mean } \\
\text { Sign Score }\end{array}$ & SD & $\begin{array}{c}\text { S Mean Sign } \\
\text { Score }\end{array}$ & SD & & \\
\hline Day 1 - Day 3 & 0.07 & 0.73 & 0.21 & 0.71 & 0.682 & 0.733 \\
\hline Day 3 - Day 10 & 0.11 & 0.78 & 0.00 & 0.68 & 0.765 & 0.829 \\
\hline Day 10 - Day 15 & 0.29 & 0.76 & 0.11 & 0.60 & 0.552 & 0.606 \\
\hline Day 1 - Day 15 & 0.43 & 1.27 & 0.33 & 0.71 & 0.956 & 1.000 \\
\hline
\end{tabular}

Over the course of the 4 visits, 23 and 21 patients were lost to in-person follow up for the DM group and the control group, respectively. While the patients were omitted from the statistical analysis, telephonic follow-up was done for all the patients that were lost to in-person follow-up. Fifteen patients (65.21\%) patients in the DM Group and nine patients $(42.86 \%)$ in the control group telephonically reported satisfactory improvement in their symptoms.

In the parallel study of 252 allergic rhinitis patients that were provided dietary counselling, 202 patients followed the diet. Out of the patients that followed the diet, 185 (91.58\%) patients reported satisfactory 
improvement in symptoms, while 17 (8.42\%) reported no improvement in their symptoms. All the 50 patients that did not follow the dietary suggestions did not report any relief in symptoms [Fig. 6].

Interestingly, the patients who were relieved of symptoms of allergic rhinitis on dietary intervention, remained symptoms free for almost 9 months. However, symptoms of rhinitis recurred in 85 patients. They reported in OPD again and were counselled to follow dietary advice and all of them showed marked improvement in their symptoms in next 6 months.

\section{Discussion}

The exclusion of DAO inhibitors, histamine rich foods, and histamine activators, and the inclusion of foods suspected to be anti-histamic resulted in $91.58 \%$ of patients that followed the advice being relieved of symptoms in the parellel study.

Without the inclusion of specific foods in the diet, just the exclusion of the DAO inhibitors, histamine-rich foods and histamine-activator rich foods the in diet significantly improved patients' conditions in the DM group within 3-7 days, as compared to the control group. In fact, the condition of the control group slightly worsened between day 3 and day 7. During the entire 15 days, from the first check to the last follow-up, the DM group's symptoms improved more significantly than those of the control group. The DM group's symptoms improved in a shorter span of time, and the overall improvement was 2.09 times better than that of the control group.

These drastic improvements in the conditions of patients in the DM group may be attributed to the fact that histamine and its precursor is largely available in the body through dietary intake14. Several commonly consumed foods are sources of exogenous histamine which gets absorbed during digestion. Moreover, histidine, the precursor of histamine, is a semi-essential amino acid as it is mostly sourced through diet itself. Some of the ingested histidine likely gets converted to histamine in the gut itself by the gastric enterochromaffin-like (ECL) cells, which are one of the top sources of endogenous histamine

\section{5,16 .}

Excluding foods containing DAO inhibitors and pro-histaminic foods from the diet of DM group might have limited the absorption of dietary histamine as well as the histamine produced by the ECL cells. Moreover, improved DAO activity throughout the body could have helped in degrading the endogenous histamine released in circulation from other cells as well. In this manner, the dietary modification may have led to lower bioavailability of histamine and helped in significantly better alleviation of symptoms in allergic rhinitis patients who followed the diet.

The dietary modification may also be coupled with other approaches such as probiotic supplement in a personalized manner may promote a healthy gut microbiome by regulating those gut-bacteria that produce histamine. 
The improving RCAT scores and Anterior rhinoscopy scores in the dietary modification group suggests that avoiding foods that are rich in histamine and histamine activators or inhibit diamine oxidase can help to control rhinitis symptoms.

The exclusion of DAO inhibitors and pro-histamine foods from the diet could also be explored in other severe conditions in which histamine is found to be elevated such as asthma. COVID-19 is also a condition in which this approach could help, as histamine release is reported to contribute to the inflammation induced by various types of coronavirus 17 . This approach may be particularly helpful as DAO and HNMT are inhibited by chloroquine18,19, a drug currently being used in the treatment of COVID19. Decrease in HNMT and DAO activity implies lesser degradation of histamine. The consequent further increase in histamine activity would fuel the cytokine storm that causes pulmonary inflammation, mucous hypersecretion, pulmonary edema and fibrosis. In this manner, the inhibition of histamine metabolising enzymes and the resulting increase in inflammatory cascades might be contributing to the respiratory distress of COVID-19 patients. Thus, simple dietary modification such as avoiding the consumption of foods rich in either histamine or histamine-activators (see Table 1) may help in the recovery of COVID-19 patients.

\section{Conclusion}

Despite the advances in otolaryngology, there is a great scope for improving the management of common conditions such as Allergic Rhinitis and Asthma. The quality of life of patients gets hampered as these conditions impair sleep quality and cognitive function which leads to further irritability and fatigue.

The restriction in the intake of foods containing diamine oxidase inhibitors and pro-histaminic foods (viz. eggs, tomatoes, peanuts, fish, preserved meat etc.) seems to have a significant role in the control of symptoms of allergic rhinitis, as indicated by the better improvement in the RCAT scores and Anterior Rhinoscopy scores of the dietary modification group compared to that of the control group.

This study highlights how simple dietary modification can alleviate symptoms faster and to a greater extent than standard treatment alone. This is because diet is the primary source of all the raw materials required for every reaction in the body.

While there is a need to further explore this approach with a bigger sample size, the employment of such dietary modification alongside standard treatment does not seem to pose any risk as long as the nutritional intakes of the patients remain adequate. Therefore, the dietary modification followed by the patients in this study may be advised to patients of allergic rhinitis and other conditions with elevated histamine levels, in addition to their standard treatments.

\section{Declarations}


Statement of Ethics Approval and Consent: This study was duly approved by the Institutional Ethics Committee at Era's Lucknow Medical College \& Hospital, Era University, Lucknow. Each patient that participated in the study was enrolled after their signed consent on the consent form.

Competing interests: The authors declare no competing interests.

Funding: The authors received no external funding for this research.

Acknowledgement: We are grateful to Dr. M.M.A. Faridi for his guidance in the study design. We also thank Dr Mohammad Faheem Khan, metabolic team members, dieticians and management team of Era's Lucknow Medical College \& Hospital, Era University, Lucknow, India for their assistance in this study.

\section{References}

1. Passali D, Cingi C, Staffa P, Passali F, Muluk NB, Bellussi The International Study of the Allergic Rhinitis Survey: outcomes from 4 geographical regions. Asia Pac Allergy. 2018 Jan 25;8(1):e7. doi: 10.5415/apallergy.2018.8.e7. PMID: 29423374; PMCID: PMC5796967.

2. Min YG. The pathophysiology, diagnosis and treatment of allergic rhinitis. Allergy Asthma Immunol 2010 Apr;2(2):65-76. doi: 10.4168/aair.2010.2.2.65. Epub 2010 Mar 24. PMID: 20358020; PMCID: PMC2846743.

3. Aberg N, Hesselmar B, Aberg B, Eriksson B. Increase of asthma, allergic rhinitis and eczema in Swedish schoolchildren between 1979 and 1991. Clin Exp Allergy. 1995 Sep;25(9):815-9. doi: 10.1111/j.1365-2222.1995.tb00023.x. PMID: 8564719

4. Leynaert B, Neukirch F, Demoly P, Bousquet J. Epidemiologic evidence for asthma and rhinitis J Allergy Clin Immunol. 2000 Nov;106(5 Suppl):S201-5. doi: 10.1067/mai.2000.110151. PMID: 11080732.

5. Ruby Pawankar, Giorgio WalkterCanonica,Stephen T. HolgateRichard F. Lockey, World Health Organization. White Book on Allergy 2011-2012 Executive Summary.

6. Varshney J, Varshney H. Allergic Rhinitis: an Overview. Indian J Otolaryngol Head Neck 2015 Jun;67(2):143-9. doi: 10.1007/s12070-015-0828-5. Epub 2015 Jan 31. PMID: 26075169; PMCID: PMC4460099.

7. Branco ACCC, Yoshikawa FSY, Pietrobon AJ, Sato MN. Role of Histamine in Modulating the Immune Response and Inflammation. Mediators Inflamm. 2018 Aug 27;2018:9524075. doi: 10.1155/2018/9524075. PMID: 30224900; PMCID: PMC6129797.

8. Caron G, Delneste Y, Roelandts E, Duez C, Herbault N, Magistrelli G, Bonnefoy JY, Pestel J, Jeannin P. Histamine induces CD86 expression and chemokine production by human immature dendritic cells. J Immunol. 2001 May 15;166(10):6000-6. doi: 10.4049/jimmunol.166.10.6000. PMID: 1342615

9. Yamauchi K, Ogasawara M. The Role of Histamine in the Pathophysiology of Asthma and the Clinical Efficacy of Antihistamines in Asthma Therapy. Int J Mol Sci. 2019 Apr 8;20(7):1733. doi: 10.3390/ijms20071733. PMID: 30965592; PMCID: PMC6480561. 
10. Krystel-Whittemore M, Dileepan KN, Wood Mast Cell: A Multi-Functional Master Cell. Front Immunol. 2016 Jan 6;6:620. doi: 10.3389/fimmu.2015.00620. PMID: 26779180; PMCID: PMC4701915.

11. Yoshikawa T, Nakamura T, Yanai K. Histamine N-Methyltransferase in the Brain. Int J Mol Sci. 2019 Feb 10;20(3):737. doi: 10.3390/ijms20030737. PMID: 30744146; PMCID: PMC6386932

12. Bousquet J, Van Cauwenberge P, Khaltaev N; Aria Workshop Group; World Health Organization. Allergic rhinitis and its impact on J Allergy Clin Immunol. 2001 Nov;108(5 Suppl):S147-334. doi: 10.1067/mai.2001.118891. PMID: 11707753.

13. Meltzer EO, Schatz M, Nathan R, Garris C, Stanford RH, Kosinski M. Reliability, validity, and responsiveness of the Rhinitis Control Assessment Test in patients with rhinitis. J Allergy Clin Immunol. 2013 Feb;131(2):379-86. doi: 10.1016/j.jaci.2012.10.022. Epub 2012 Dec 6.

PMID: 23219170

14. Malone $\mathrm{MH}$, Metcalfe Histamine in foods: its possible role in non-allergic adverse reactions to ingestants. N Engl Reg Allergy Proc. 1986 May-Jun;7(3):241-5. doi: 10.2500/108854186778995301. PMID: 3302658.

15. Cui G, Waldum HL. Physiological and clinical significance of enterochromaffin-like cell activation in the regulation of gastric acid secretion. World J Gastroenterol. 2007 Jan 28;13(4):493-6. doi: 10.3748/wjg.v13.i4.493. PMID: 17278212; PMCID: PMC4065968.

16. Fogel WA, Lewinski A, Jochem Histamine in food: is there anything to worry about? Biochem Soc Trans. 2007 Apr;35(Pt 2):349-52. doi: 10.1042/BST0350349. PMID: 17371276.

17. Kritas SK, Ronconi G, Caraffa A, Gallenga CE, Ross R, Conti Mast cells contribute to coronavirusinduced inflammation: new anti-inflammatory strategy [published online ahead of print, 2020 Feb 4]. J Biol Regul Homeost Agents. 2020;34(1):10.23812/20-Editorial-Kritas. doi:10.23812/20-EditorialKritas

18. Leitner R, Zoernpfenning E, Missbichler A. Evaluation of the inhibitory effect of various drugs / active ingredients on the activity of human diamine oxidase in vitro. Clin Transl Allergy. 2014 Jul 18;4(Suppl 3):P23. doi: 10.1186/2045-7022-4-S3-P23. PMCID: PMC4127955.

19. Pacifici GM, Donatelli P, Giuliani L. Histamine N-methyl transferase: inhibition by drugs. Br J Clin Pharmacol. 1992 Oct;34(4):322-7. doi: 10.1111/j.1365- 2125.1992.tb05637.x. PMID: 1457266; PMCID: PMC1381414

\section{Figures}


<smiles>NCCc1c[nH]cn1</smiles>

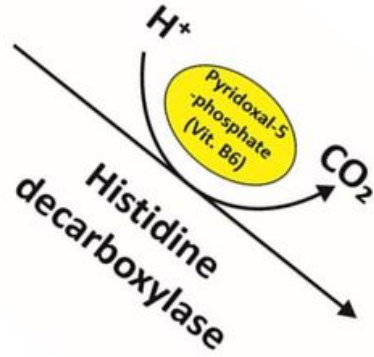

Histamine Rich food

(Egg, Tomato, Soyabean, Peanuts, Fish, Chocolate etc.)

\section{Figure 1}

Histamine Biosynthesis and Food Sources

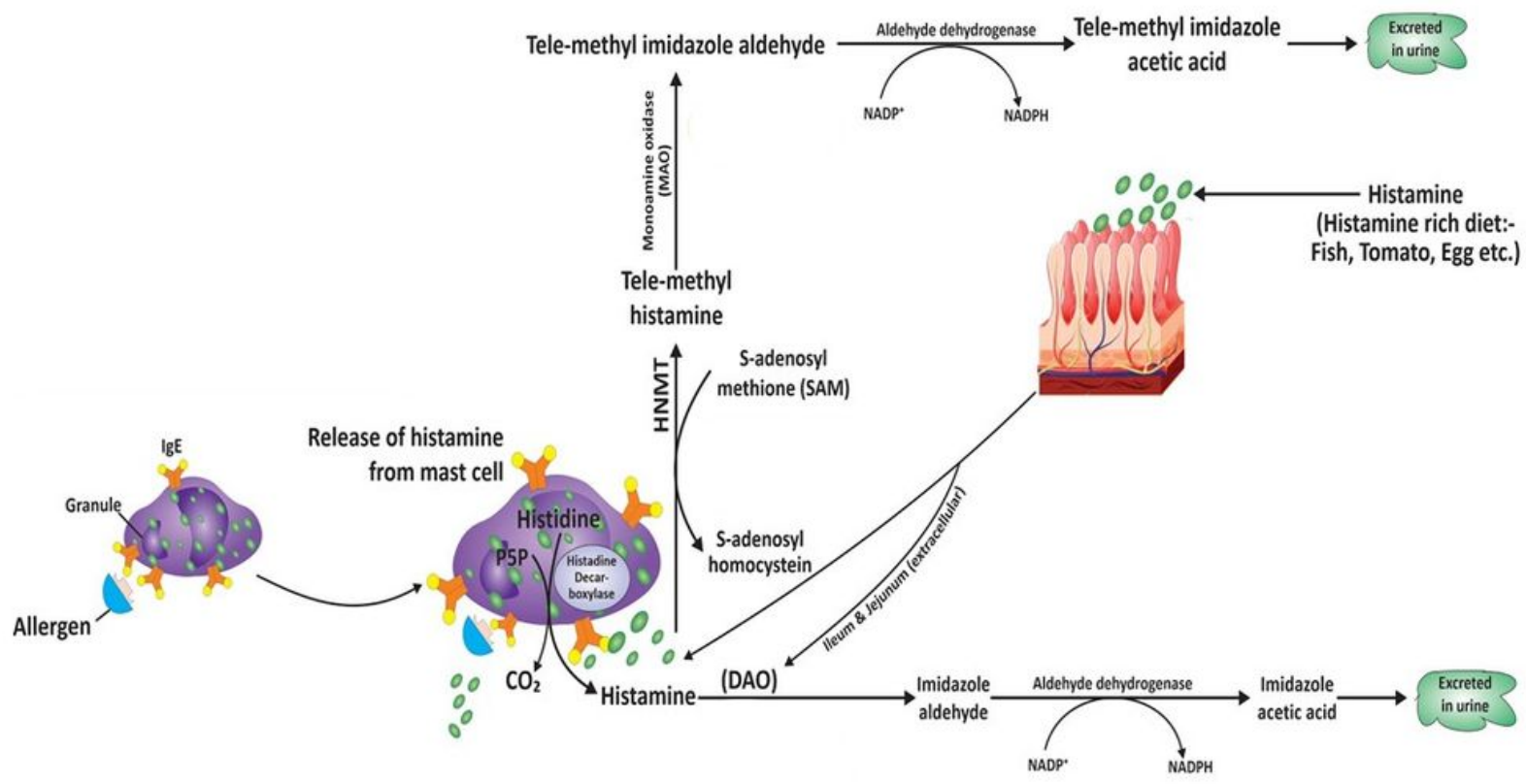




\section{Figure 2}

Histamine Degradation by HNMT \& DAO

\section{ALLERGIC RHINITIS PATIENT FOLLOWUP FLOW CHART}

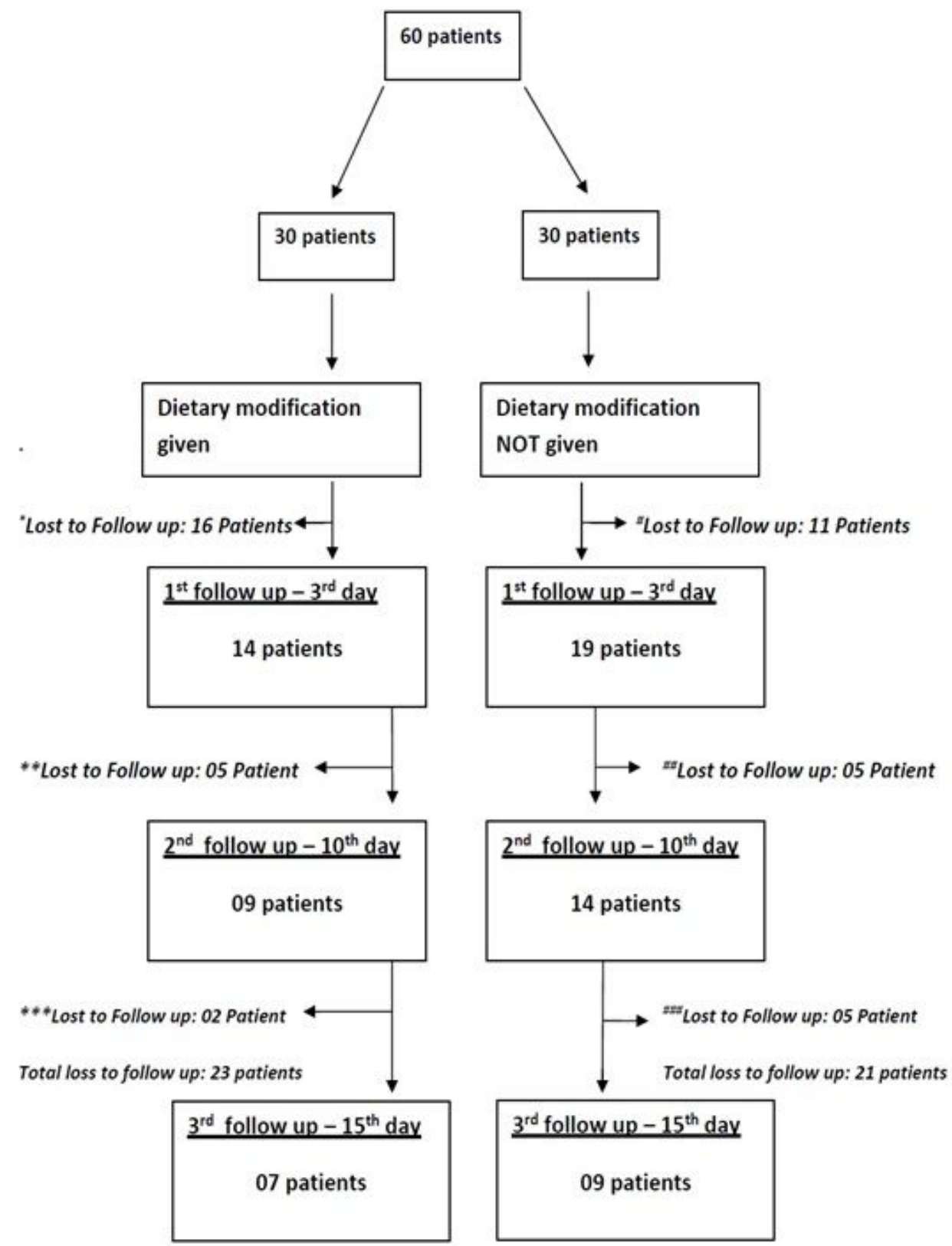

Patient's lost to follow up were inquired regarding improvement in symptoms on telephone. Following number of patients reported improvement. Symbols corresponds to as used above -

*10 Patients

**3 Patients

$* * * 2$ Patients
\#5 Patients

\#\#2 Patients

\#\#\#2 Patients

\section{Figure 3}

Flowchart of Patient Follow-up 


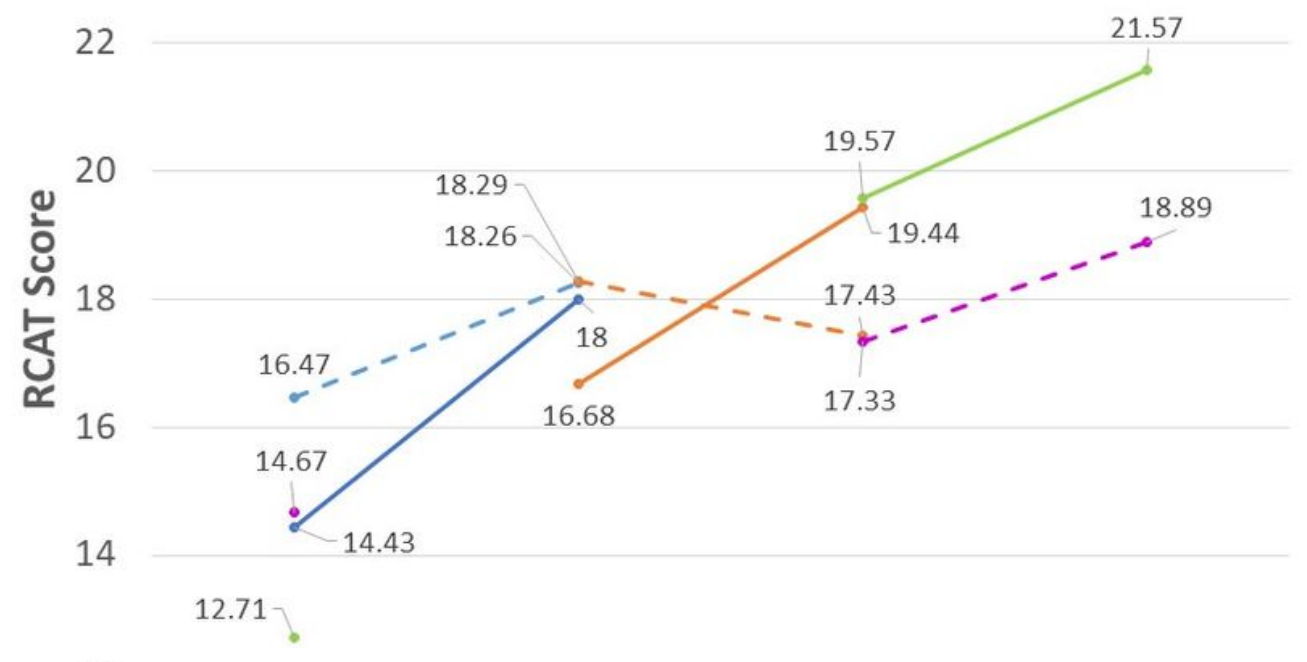

12

Day 1 Day 3 Day $10 \quad$ Day 15

$\rightarrow$ DM Group | V1-V2 | n=14 $\quad$-DM Group | V2-V3 | n=9 $\quad$ DM Group | V3-V4 | n=7

- - Control Group | V1-V2 | n=19 - - Control Group | V2-V3 |n=14 - - Control Group | V3-V4 | n=9

\section{Figure 4}

Variation in Mean Rhinitis Control Assessment Test (RCAT) Scores

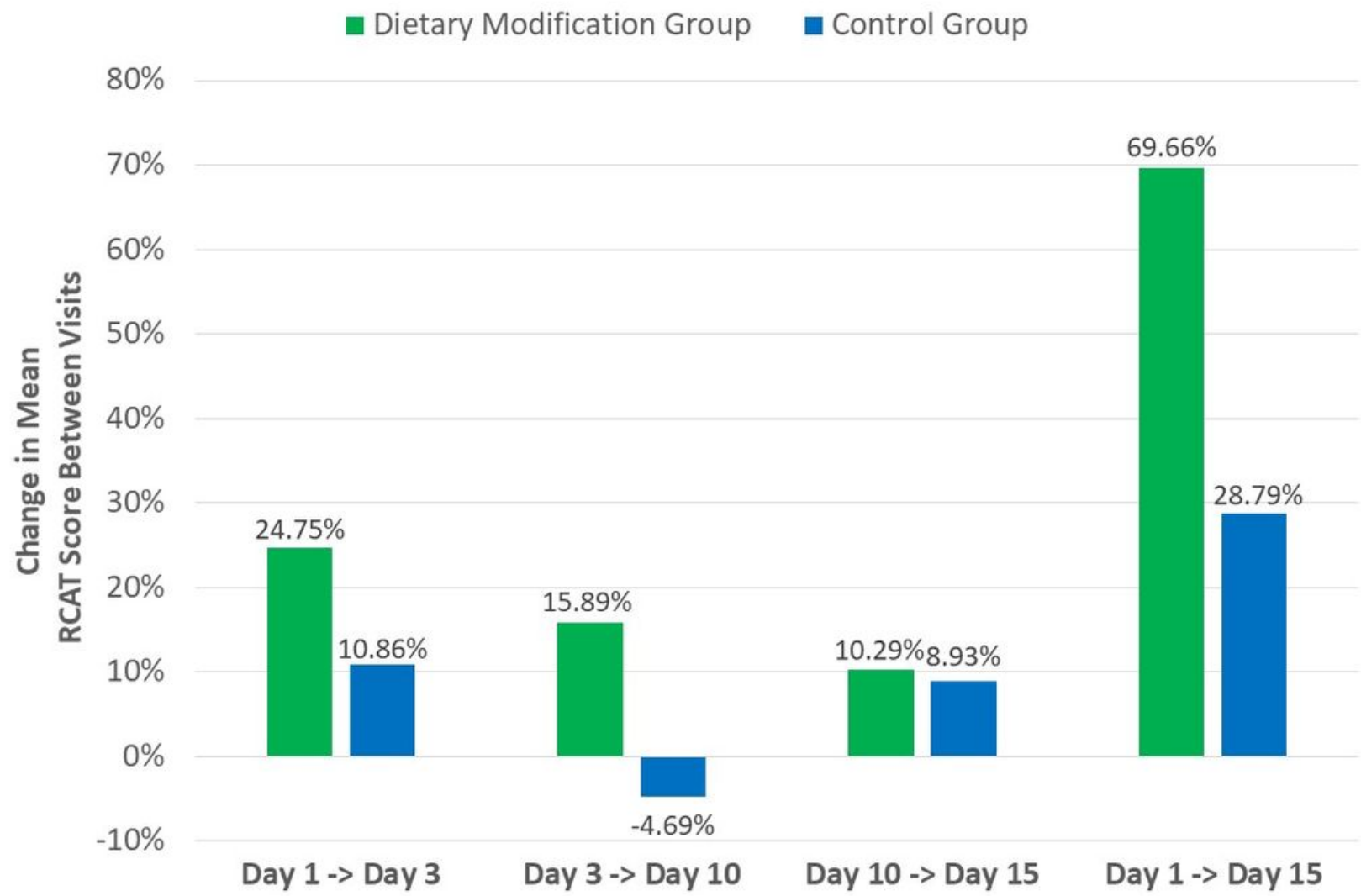


Figure 5

Percentage of Change in RCAT Score Between Visits

$$
0.50
$$

0.45

0.40

0.35

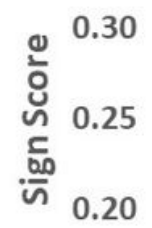

0.15

0.10

0.05

0.00
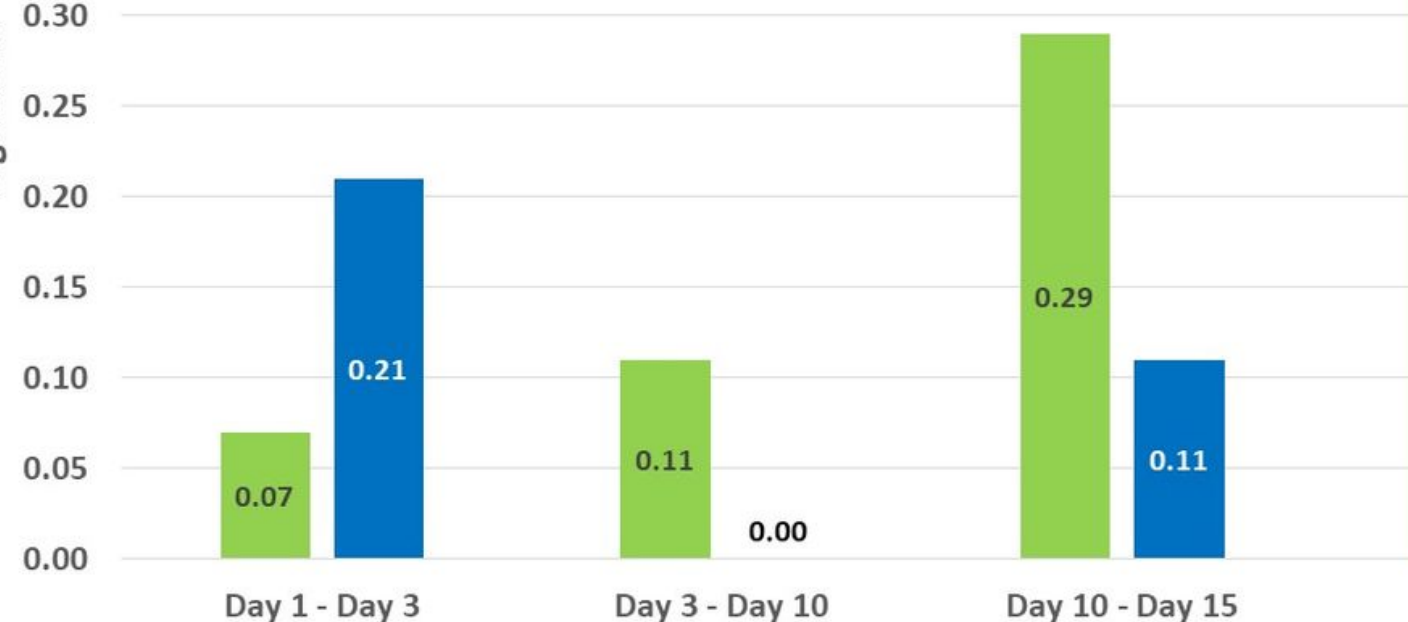

0.20

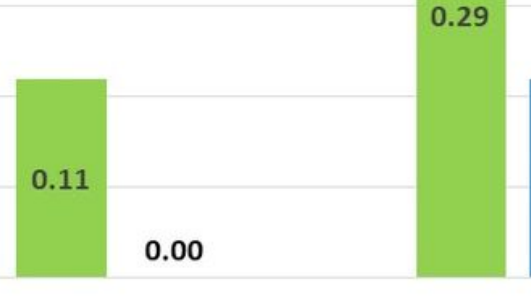

Day 10 - Day 15
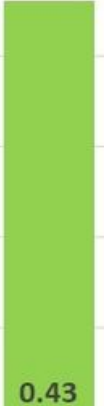

0.43
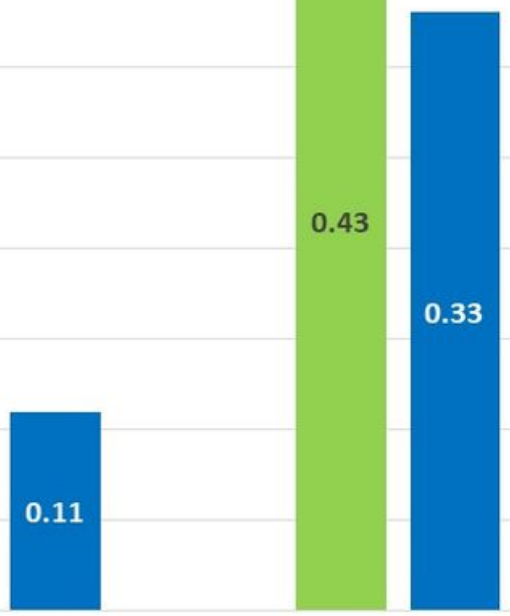

nietary Modification Group

- Control Group

\section{Figure 6}

Change of Sign Score Between Visits 


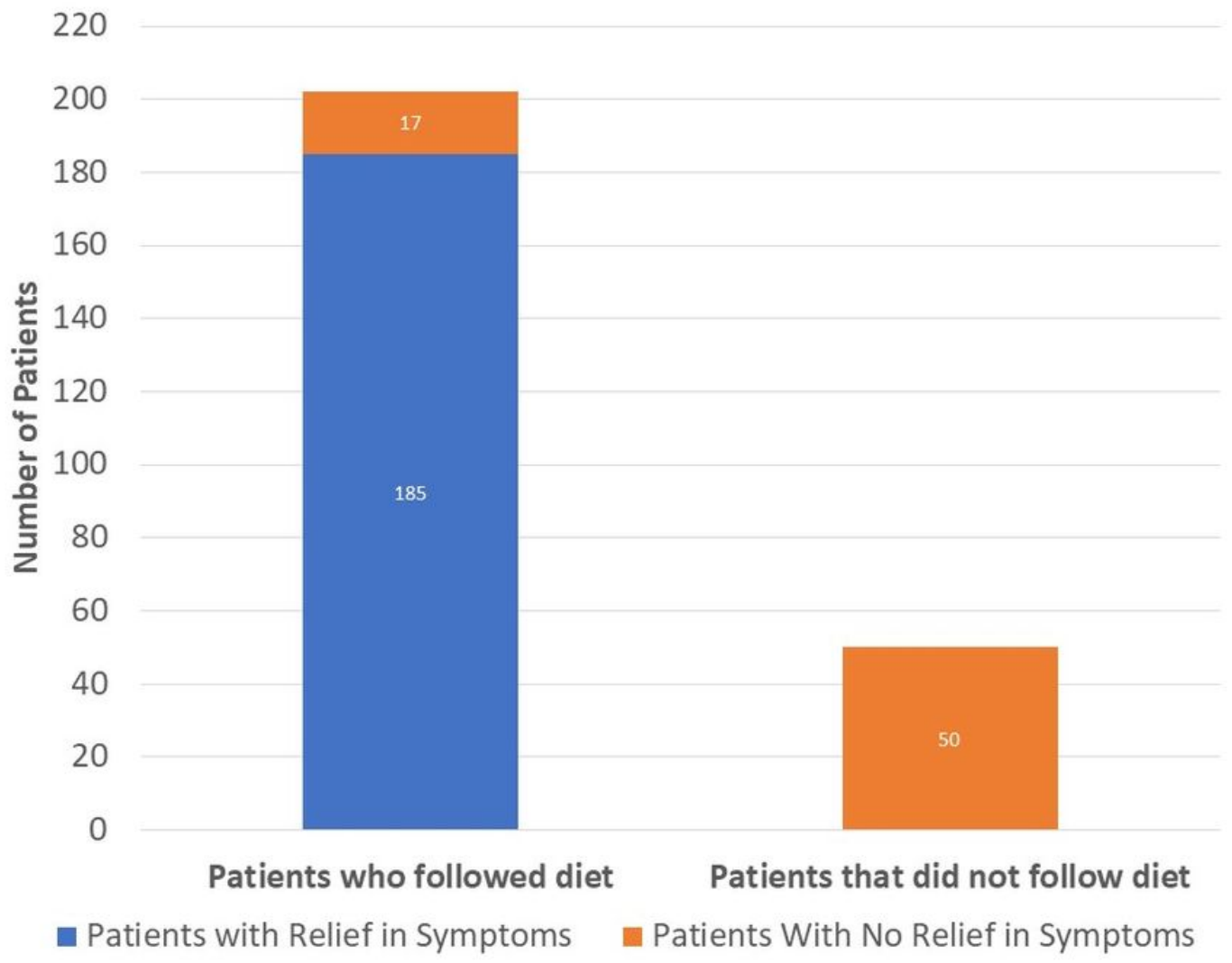

Figure 7

Patient Outcomes in The Parallel Study

\section{Supplementary Files}

This is a list of supplementary files associated with this preprint. Click to download.

- Annexures.pdf 